\title{
Managing Plant Pests with Soaps ${ }^{1}$
}

\author{
Matthew A. Borden and Adam G. Dale ${ }^{2}$
}

A topic frequently discussed by home gardeners and professionals is the use of soap products to control plant pests. Limited and conflicting information on this topic has resulted in confusion and misuse of products. This document describes some of the different types of soaps and recommendations for proper, legal, and safe use of these products to manage pests.

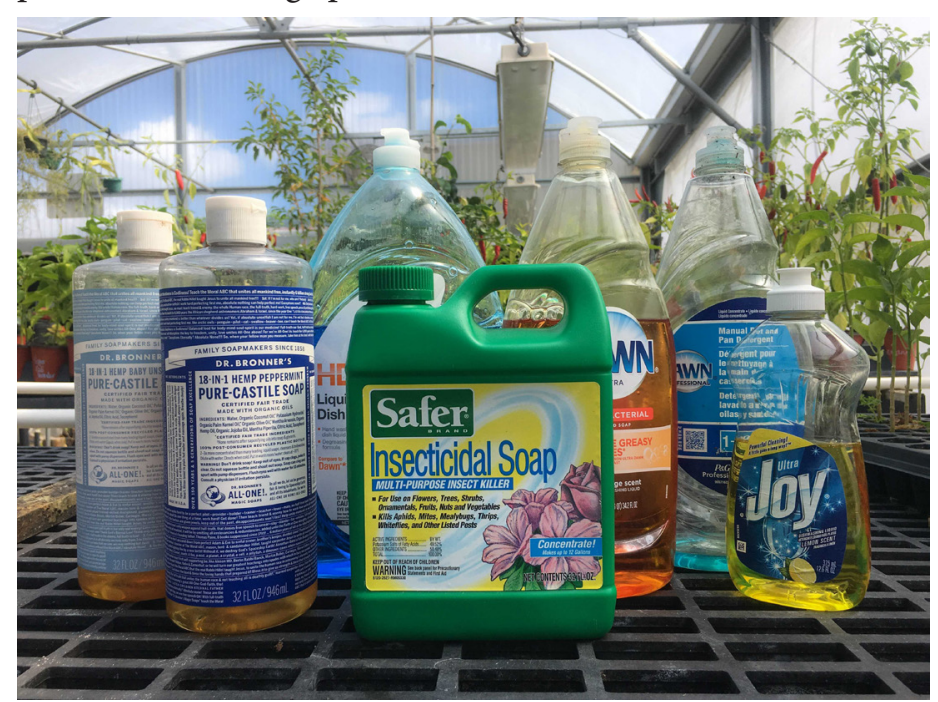

Figure 1. Many available products are referred to as "soap," but not all are appropriate or safe to use for insect or mite pest management. Credits: Matthew Borden, UF/IFAS

\section{All Soaps Are Not the Same Insecticidal Soaps}

Insecticidal soaps are formulated specifically to control insect and mite pests. They are intended to be relatively safe for plants when following the label instructions. Insecticidal soaps are affordable and effective against many soft-bodied pests such as aphids, soft scales, psyllids, whiteflies, mealybugs, thrips, and spider mites. For these common pests, just two applications 5-7 days apart are often enough to greatly reduce their population. Like horticultural oils, insecticidal soap sprays must directly contact the pests to be effective. Residues that remain on plants after drying have no insecticidal effect.

Insecticidal soap products typically contain potassium salts of fatty acids. The fatty acids are naturally found in fats and oils of animals (lard, fish oil) and plants (cottonseed, olive, palm, coconut oils). Most modern soaps are produced using sodium hydroxide, a very efficient modern lye. However, insecticidal soaps are made by saponification with potassium hydroxide, a traditional lye. While soaps produced by either process will kill soft-bodied organisms, the sodium found in modern soaps is toxic to plants, and excessive use can leave a damaging amount of sodium ions (negatively charged molecules that can dry out plant tissue) on the plant surface.

1. This document is ENY344, one of a series of the Entomology and Nematology Department, UF/IFAS Extension. Original publication date June 2019. Visit the EDIS website at https://edis.ifas.ufl.edu for the currently supported version of this publication.

2. Matthew A. Borden, graduate research assistant, Entomology and Nematology Department; and Adam G. Dale, assistant professor, Entomology and Nematology Department; UF/IFAS Extension, Gainesville, FL 32611.

The Institute of Food and Agricultural Sciences (IFAS) is an Equal Opportunity Institution authorized to provide research, educational information and other services

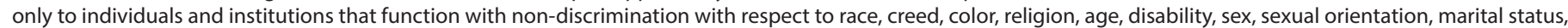

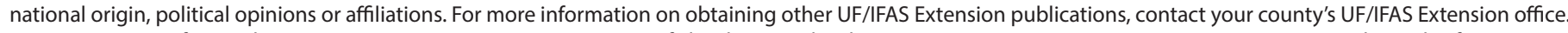
U.S. Department of Agriculture, UF/IFAS Extension Service, University of Florida, IFAS, Florida A \& M University Cooperative Extension Program, and Boards of County Commissioners Cooperating. Nick T. Place, dean for UF/IFAS Extension. 


\section{Dish Soaps}

Unlike insecticidal soaps, dish soaps are not designed for pest control purposes or for use on plants. There are several common misperceptions about dish soaps that contribute to their misuse in the landscape. We attempt to clarify those misperceptions below:

\section{Is dish soap/detergent a natural or organic alternative} to pesticides? Most dish soap products are not true soaps, but powerful surfactants called detergents. These products consist of synthetically produced detergents and other chemicals designed to strip grease and oily residue off cookware and other surfaces. These soaps work extremely well for cleaning and sanitation purposes. Directions for proper use can be found on a product label and the safety data sheet (SDS). If the company does not include uses on garden plants or as a pesticide then the product should not and may not be used as such. Dish detergents (e.g., Dawn ${ }^{\circledR}$, Joy ${ }^{\circledR}$, Palmolive ${ }^{\circledR}$ ) are not an organic alternative to pesticides and are not appropriate for pest control in organic or conventional gardening.

Is dish detergent a safe way to kill pests without harming beneficial organisms? Detergents can kill many pests. However, they do not discriminate between harmful, helpful, or harmless organisms (to learn more, see "Helpful, Harmful, Harmless: Insects and other Organisms of Florida Landscapes" available in the UF/IFAS Extension bookstore, http://ifasbooks.ifas.ufl.edu). Detergents can damage many soft-bodied insects and mites, both good and bad. They also frequently contain antimicrobial ingredients and can severely disrupt microorganisms (including beneficial insect-parasitic fungi) contacted by the detergent.

Is dish detergent harmless to plants? The powerful oilstripping properties of detergents and concentrated soaps are believed to severely disrupt the delicate layer of wax on the surfaces of plant leaves and fruits. Similar in function to our skin, a plant's waxy cuticle is the primary mechanical defense against microbial, viral, and fungal invasion. The waxy cuticle also acts as a barrier against water and solute loss. If a plant loses this protective layer, it will lose more water by transpiration, and its foliage will dry out. Plants adapted to drought, low humidity, and strong sunlight (such as succulents) typically have a much thicker waxy cuticle layer to help protect against water loss and may be more susceptible than other types of plants to detergent damage.

\section{All About the Rate}

Any soap (even true insecticidal soaps) can cause leaf burn and injury to plants (called phytotoxicity) (Figures 2 and 3) and can be harmful to beneficial insects if used incorrectly. Inconsistency in the application rate, or amount of soap per volume of water, causes many of the problems associated with using dish detergents and other soap products as pesticides. Recipes from gardening websites or homemade mixes can vary widely, from 1 tsp/quart to $1 / 4$ cup/quart, and often include other potentially phytotoxic ingredients, such as vinegar and alcohols. These recipes fail to consider the type of soap and safe application rates, environmental cautions, target pest type, and sensitivity of the plants.

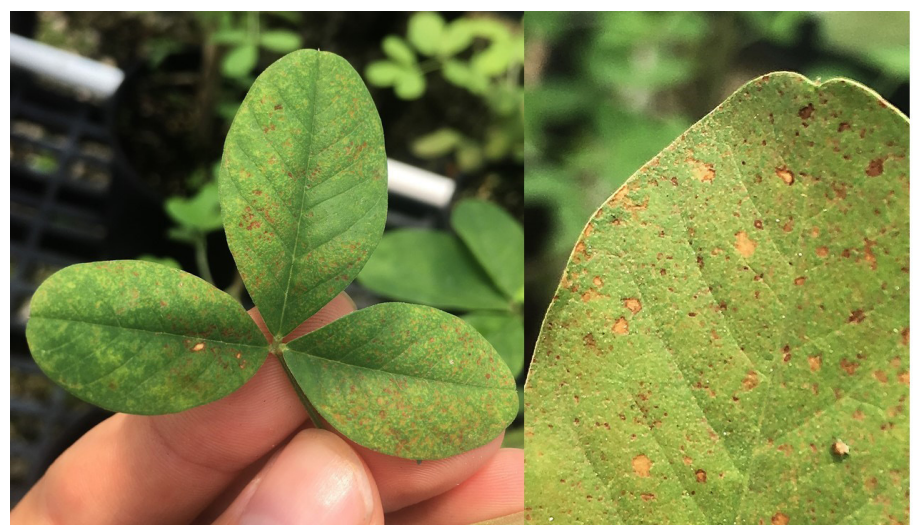

Figure 2. Phytotoxicity on a rattlebox plant (Crotalaria sp.) appearing as chlorosis and necrotic pitting. This was caused by an application of dish detergent mixture the previous day intended to control aphids. Credits: Matthew Borden, UF/IFAS

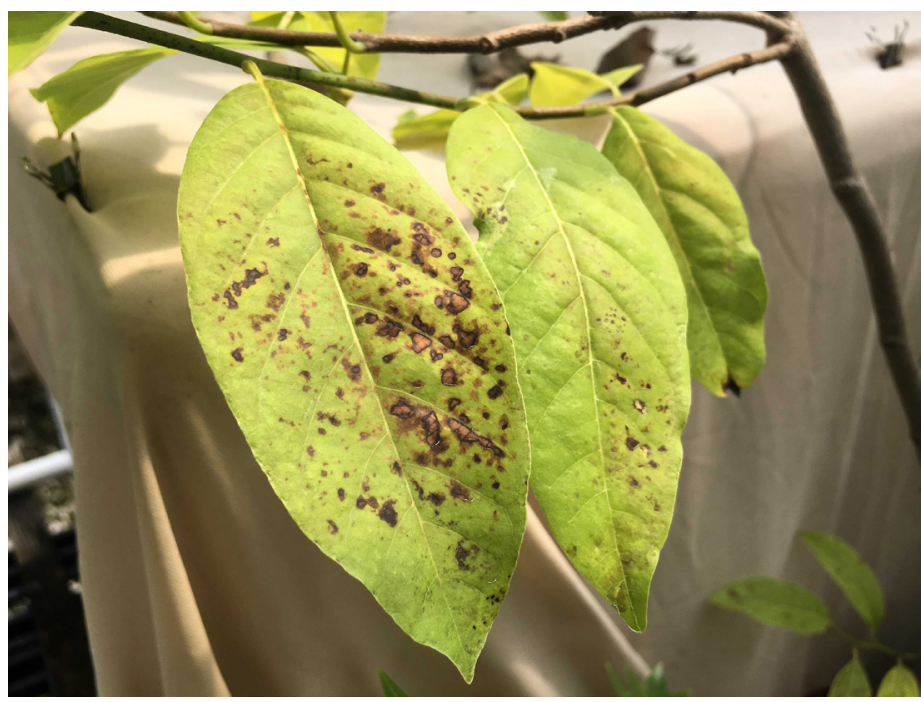

Figure 3. Phytotoxicity on a stressed sugar-apple (Anona sp.) tree caused by an insecticidal soap application on a hot, sunny afternoon. Credits: Matthew Borden, UF/IFAS

Properly registered insecticidal soap products usually recommend an application rate between $1 \%$ to $2 \%$ soap per volume of water to minimize plant damage while effectively controlling soft-bodied insect and mite pests. Not only does a registered product label provide consistent rate 
recommendations, but it also clearly states which species and cultivars of plants may be sensitive and should not be sprayed, among them crown of thorns, fuchsia, bleeding heart, lilies, and sweetpeas. Delicate ferns, waxy succulents, and plants with hairy leaves can be especially sensitive.

It is also important to know when not to use insecticidal soaps for abiotic (environmental) reasons. Plants should never be treated with soaps if they are already under stress from drought or excessive humidity or when temperatures exceed $90^{\circ} \mathrm{F}$. A helpful practice to reduce risk of plant damage is to always test the soap product on a few leaves before treating the entire plant.

\section{Suggested Guidelines for Use}

Because detergents and other household soaps are neither designed nor labeled for use on plants or as pest control products, their use as a makeshift pesticide is not recommended. However, they can still be useful for other indoor and outdoor purposes:

\section{Use detergent and water as a scouting tool for turfgrass} insect pests. Some pests, such as mole crickets and caterpillars, hide deep in turfgrass and are difficult to detect. Drenching a small area of turf with soapy water can irritate the pests and cause them to temporarily come to the surface where they can be identified and counted. Note that this practice does not control the pest. Rather, it is a monitoring tool used to determine presence, life stage, and abundance of a pest so that you can choose an appropriate treatment action.

\section{Use soapy water and a soft brush to scrub scale insects off} trunks and branches of infested plants (woody plant tissue). While this not an efficient or highly effective method for controlling a scale insect infestation, it can remove debris and dead scales that build up during severe infestations. The cleaner, less obstructed surface helps follow-up insecticide treatments to be more effective at controlling the pest and improves the plant's aesthetic value.

\section{Use for indoor sanitation. Soapy water can be useful} indoors to clean up dead insects and insect allergens that may be present, to erase the chemical signals that insects use to communicate (such as ant trails), and to remove food residues attractive to insects. When used for sanitation purposes, soapy water is cheaper and safer than some other cleaning products.

4. Use to emulsify an oil + water solution. Certain naturally derived substances are given an Environmental
Protection Agency (EPA) exemption for use in minimum-risk pesticide products. These include many oils such as soybean, sesame, garlic, clove, corn, and various herbal extracts (see the full list here). Commercial formulations of pesticide oils, including horticultural and neem oils, contain an emulsifying agent to help the product form a stable mix with water so that it can be evenly applied. Oils not in a prepared formulation must be emulsified manually to ensure proper application coverage. Although there are emulsifying agents designed for this purpose, nearly all are for professional pesticide applications. Therefore, if none are available, homeowners may use a few drops of castile soap or detergent to emulsify an oil solution (Figure 4).

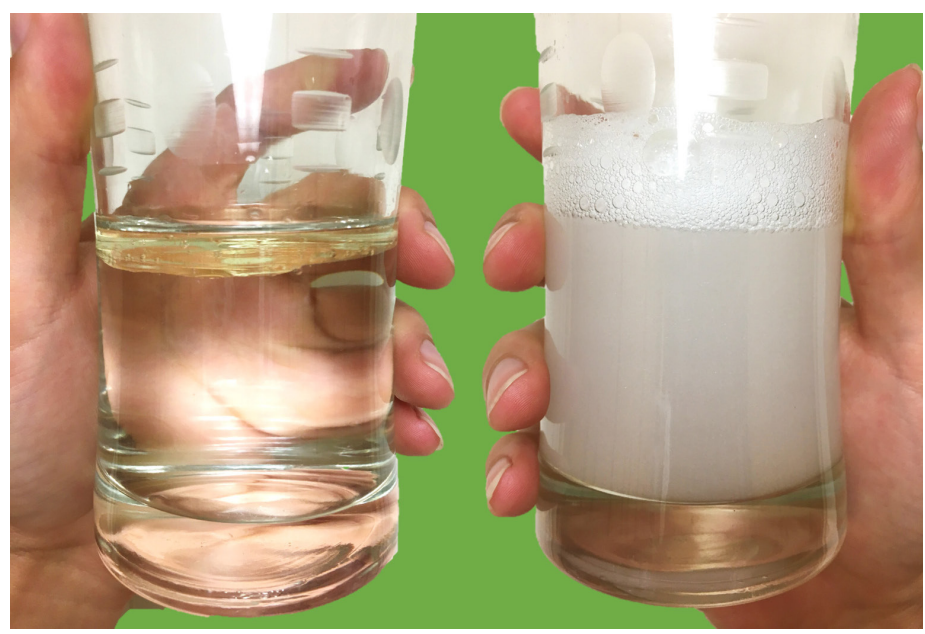

Figure 4. The left glass contains only oil and water, which rapidly separate after being shaken together. The same solution at right has been stirred and emulsified by a drop of detergent.

Credits: Matthew Borden, UF/IFAS

\section{Other Soap Products}

\section{Castile Soap Products}

Castile soaps are produced with vegetable oils (particularly olive, palm, and coconut), which could be made into insecticidal soap products containing potassium salts of fatty acids. However, most castile soaps are mixed with fragrances and essential oils to be sold for a wide range of household cleaning or cosmetic purposes. Some castile soap products, such as Dr. Bronner's soaps, are often mistaken as safe insecticides. While these products are not registered as pesticides, the labels or product websites (which is considered supplemental label information) sometimes include recommendations for controlling pests on plants.

However, according to the EPA, soaps currently meet neither the ingredient nor labeling criteria, and thus do not qualify for a pesticide registration exemption and are not minimum-risk pesticides. The EPA's minimum-risk pesticide (MRP) criteria can be found here: Minimum Risk 
Pesticides. The list of active ingredients that can be used in minimum-risk products can be found here: Active Ingredients Eligible for Minimum Risk Pesticide Products.

\section{Ivory Soap Products}

Some gardeners speak positively about the pest control use of original Proctor \& Gamble ${ }^{\circledR}$ Ivory soaps, but Ivory products have been expanded and reformulated. There are also reports of plant damage and yield reduction caused by these newer products, especially liquid formulations that contain detergents and sodium-based components, including salt. These products, including new bar soap formulations, are not intended for use in pest control or on plants. Therefore, we do not recommend their use for pest control.

We advise against the use of products that are not registered by the EPA for several reasons:

1. These products may not be "safe" at all. In fact, many household chemicals are quite toxic to plants, animals, and people. Some can present significant safety hazards, especially in concentrated forms.

2. These products may cause unnecessary plant injury because there is no established information (and a great deal of conflicting information) on how to apply them, which concentration to use, and which plants may be sensitive to damage.

3. There is far more room for error and little assurance that homemade mixes will control a pest problem. This is often frustrating and expensive and allows the pest population to become even more damaging.

4. Many recommendations for homemade pesticides stem from so-called "click-bait" gardening websites and other unvetted media sources. We recommend using university and Cooperative Extension publications and resources for evidence-based pest management recommendations.

5. It is illegal to spray unregistered chemicals of any sort on crops that will be sold commercially as food. Therefore, it can become a legal and food-safety problem if a grower with innocent intentions is advised to spray their commodity with unregistered substances.

\section{Conclusion}

Insecticidal soap products are chemically similar to other household soaps but are designed for pest control on plants. While other soaps found in the home may also kill softbodied insects and mites, they are often not as effective and pose greater risk of injury to the plant and environment. Dish soap products, designed to remove tough grease and oils, may be particularly damaging to a plant's waxy cuticle because they contain synthetic detergents and other potentially phytotoxic chemicals. If your dish detergents, other household soaps, and assorted household chemicals are neither designed nor labeled for use on plants or in pest control, we caution against and do not recommend their use as such.

\section{References}

Caldwell, B., E. Sideman, A. Seaman, A. Shelton, and C. Smart. 2013. Resource Guide for Organic Insect and Disease Management. 2nd edition. Cornell University. (New York State Agricultural Experiment Station). 150 pp. http://web. pppmb.cals.cornell.edu/resourceguide/pdf/resource-guidefor-organic-insect-and-disease-management.pdf

Cranshaw, W. 2008. Insect Control: Soaps and Detergents. Colorado State University Extension Fact Sheet No. 5.547 http://extension.colostate.edu/docs/pubs/insect/05547.pdf

Curkovic, T. 2016. Detergents and Soaps as Tools for IPM in Agriculture. In Integrated Pest Management (IPM): Environmentally Sound Pest Management. InTech.

Gutschick, V. 1999. "Biotic and abiotic consequences of differences in leaf structure." New Phytologist 143(1) 3-18.

Hadley, N. 1980. "Surface Waxes and Integumentary Permeability: Lipids deposited on or associated with the surface of terrestrial plants and animals help protect them from a lethal rate of desiccation." American Scientist 68 (5) 546-553.

Kostka, K. and D. D. McKay. 2002. "Chemists Clean Up: A History and Exploration of the Craft of Soapmaking-How Soap Came to be Common in America." Journal of Chemical Education 79 (10) p.1172. https://pubs.acs.org/doi/ pdf/10.1021/ed079p1172

Rieske, Lynne K., Stacy Borden, Brianna Damron, Nic Williamson, Mary Arthur, Adrienne Kinney. 2019. "College Campus as a Living Laboratory: Scrubbing Scales, Saving Trees, Engaging Students." American Entomologist Volume 65, Issue 1, Spring 2019, Pages 43-49, https://doi. org/10.1093/ae/tmz010

National Pesticide Information Center. 2001. Potassium Salts of Fatty Acids (Technical Fact Sheet). 
Pundt, L. Updated 2015. Insecticidal Soaps. University of Connecticut Integrated Pest Management Program. http:// ipm.uconn.edu/documents/raw2/800/2015insecticidalsoap factsheet..pdf.

Sclar, D. C., D. Gerace, A. Tupy, K. Wilson, S. A. Spriggs, R. J. Bishop, and W. S. Cranshaw. 1999. "Effects of application of various reduced-risk pesticides to tomato, with notes on control of greenhouse whitefly." HortTechnology 9 (2) $185-189$. 